\title{
Recycling Light Metals: Optimal Thermal De-coating
}

\author{
Anne Kvithyld, C.E.M. Meskers, Sean Gaal, Markus Reuter, and Thorvald Abel Engh
}

Thermal de-coating of painted and lacquered scrap is one of the new innovations developed for aluminum recycling. If implemented in all recycling and optimized as suggested in this article, recovery would be improved with considerable economic impact. Generally, contaminated scrap is difficult to recycle. Direct re-melting of coated scrap results in the generation of gaseous emissions, with increased metal oxidation, contamination, and salt flux usage. By thermal de-coating of the scrap these problems are avoided. Thermal de-coating followed by remelting of aluminum scrap is now common practice, while painted magnesium scrap is not currently de-coated and recycled. This article presents observations during heating of the contaminated light metals together with the mass loss, evolved gases, and residue after de-coating in order to give a general description of the de-coating process. It is argued that the main behavior during de-coating may be described as two distinct regimes-scission and combustion-regardless of metal substrate and coating. Monitoring the combustion regime should assure optimum de-coating.

\section{INTRODUCTION}

Recycling is a key issue in creating sustainable, closed material cycles as it conserves material and energy resources while reducing the emission of $\mathrm{CO}_{2}$. Recycling light metal scrap (including the treatment of salt slag) consumes only $12 \%$ of the energy required to produce primary aluminum. ${ }^{1}$ Additionally, recycling end-of-life products reduces the amount of material deposited in landfills. The large quantity of available scrap and its high intrinsic value make light metals recycling economi- cally viable.

In 2006 global aluminum production was 60.4 million tonnes, which comprised $56 \%$ primary metal and $44 \%$ recycled metal. ${ }^{2}$ Within the European Union domestic production of recycled aluminum is higher than for primary production. ${ }^{3}$ The proportion of coated scrap is not known. However, most post-consumer aluminum surfaces are modified and coated to give corrosion resistance and a nice appearance.

Coated (painted) aluminum used for packaging (beverage cans), automotive applications, consumer electronics, and building and interior applications is more difficult to recycle. The complex-

\section{$\nexists$ How would you...}

...describe the overall significance of this paper? If thermal decoating was Z implemented in all recycling and optimized as suggested in this article, recovery of metal would be improved with considerable ecological economic impact.

...describe this work to a materials science and engineering professional with no experience in your technical specialty?

Observations during heating of the coated light metals are presented together with the mass loss, evolved gases, and residue after decoating in order to give a general description of the de-coating process.

...describe this work to a layperson?

Thermal de-coating followed by re-melting of aluminum is common practice. This article shows the main behavior during de-coating may be described as two distinct regimes-scission and combustion-regardless of metal substrate and coating. ity of recycling scrap increases with the amount of coating. Direct re-melting of coated scrap results in the generation of large amounts of gaseous emissions due to the decomposition of the organic material used in the coating. The carbon partially reacts with aluminum to form aluminum carbide $\left(\mathrm{Al}_{4} \mathrm{C}_{3}\right)$, which is found in the salt slag. During slag storage and recycling the carbides react with water, releasing methane, ${ }^{4}$ which should be captured and controlled to avoid an adverse environmental impact. Furthermore, aluminum metal is lost due to increased oxidation and intermetallics formation, reducing metal quality. To capture solid particles present during re-melting salt flux is added, resulting in increased salt slag quantities that have to be treated.

Removal of the organic coatings by thermal treatment prior to re-melting will help prevent the above-mentioned phenomena. Volatilization and pyrolysis of the coating take place during the scission phase, creating gasses, liquid tar, and solid char. Off-gasses generated during de-coating are captured and the organic compounds are combusted to recover the energy, which can then be used to heat the de-coating unit. Subsequently, the carbon residue reacts with the oxygen in the combustion phase, generating $\mathrm{CO}, \mathrm{CO}_{2}$, and heat (see Figure 1), leaving a surface with the inorganic pigment and filler particles from the organic coating. ${ }^{5}$ Removal of the inorganic material from the coating that is left on the surface is also necessary to maintain melt cleanliness.

The scrap should be heated to 500$630^{\circ} \mathrm{C}$ depending on the substrate, gas atmosphere, and composition of the organic layer. Thermal de-coating is not suitable for thermally fragile substrates or for the removal of high temperature 


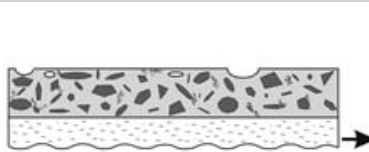

Coated metal substrate

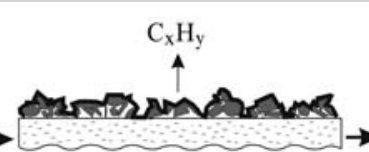

Scission

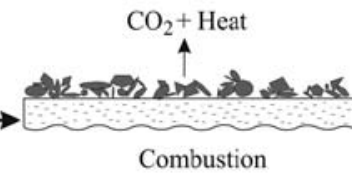

Combustion

Figure 1. A schematic representation of thermal de-coating. First, scission occurs where the coating decomposes, releasing hydrocarbons and leaving pigment/fillers/carbon residue. Combustion follows, where the carbon residue on the surface is burnt in the presence of $\mathrm{O}_{2}$. Inorganic material remains on the surface.

resistant organic coatings. ${ }^{6}$ Residence time and gas flow rates are also important parameters. Thus, to optimize the de-coating process of aluminum scrap, it is necessary to determine the optimum time, temperature, and atmosphere in the reactor so that the coating is removed, while under-exposure (incomplete coating removal) and overexposure (oxidation of aluminum after coating removal) is avoided.

Thermal degradation of organic coatings like polyester and epoxy has been studied extensively using thermogravimetric / differential thermal analysis (TG/DTA).$^{7-9}$ However, these studies are often made on tailor-made coatings and mostly without metal substrates. Degradation analysis is employed to describe and characterize only a special coating and is therefore not always useful. The goal here is a description that can be used to control industrial de-coating processes. In this paper the thermal degradation mainly of acrylic and polyester coatings on aluminum is investigated using TG/ DTA to simulate the de-coating process, combined with hot stage microscopy to observe the coating during heating. In this manner the influence of the aluminum substrate on the process conditions can be taken into account. The results and model can be used to control industrial de-coating processes.

\section{CHARACTERIZATION OF COATED SCRAP}

The investigation was conducted on samples cut from industrial coil coated aluminum sheets. One was an acrylic coating, white in appearance, and the other was a transparent polyester coating. The one-sided acrylic coated aluminum, almost $1 \mathrm{~mm}$ thick, was provided by Aleris International Inc. In the coating pigment and filler particles are present to provide the white color. The film thickness was around $20 \mu \mathrm{m}$. The back of the metal was ground to remove some of the aluminum, increasing the coating percentage to approximately 10 wt.\%.

The two-sided polyester coated aluminum sheet (total $0.42 \mathrm{~mm}$ thick) was produced at Norsk Hydro ASA. The coating was $5 \mu \mathrm{m}$ thick polyester, which contained polyester (56\%), polyurethanes $(17 \%)$, amino resins $(16 \%)$, epoxy $(5 \%)$, pigments and wax $(5 \%)$, and acid catalyst $(1 \%)$. This composition shows that even though the coating is labeled polyester, it is nearly half other substances.

Evidently coatings are complex mixtures of materials in which a range of organic and inorganic components is present. The precise composition is dif- ficult to determine, especially for materials from end-of-life products, and requires that the de-coating process is able to deal with the range of unknown coatings entering the recycling process.

In practice, the re-melters consider only the mass percent of the coating. Over the years the trend has been that the metal thickness in design has decreased. However, this is also true for coating thickness. A study of beverage cans 20 years apart shows an almost identical ratio between the coating and metal.

\section{VISUALIZING THERMAL DE-COATING}

A hot stage microscope (Linkam TS1500) with a TMS 93 temperature controller was used to observe the decoating process (Figure 2). The temperature program and gas atmosphere were chosen to correspond to the decoating process.

The simulation was performed in a TG/DTA furnace coupled to a mass spectrometer (MS). In the TG/DTA the mass loss, change in mass loss, and enthalpy change during de-coating were measured and the MS provided information about the evolved gases as a function of time and temperature. Experimental conditions and the TG/DTA

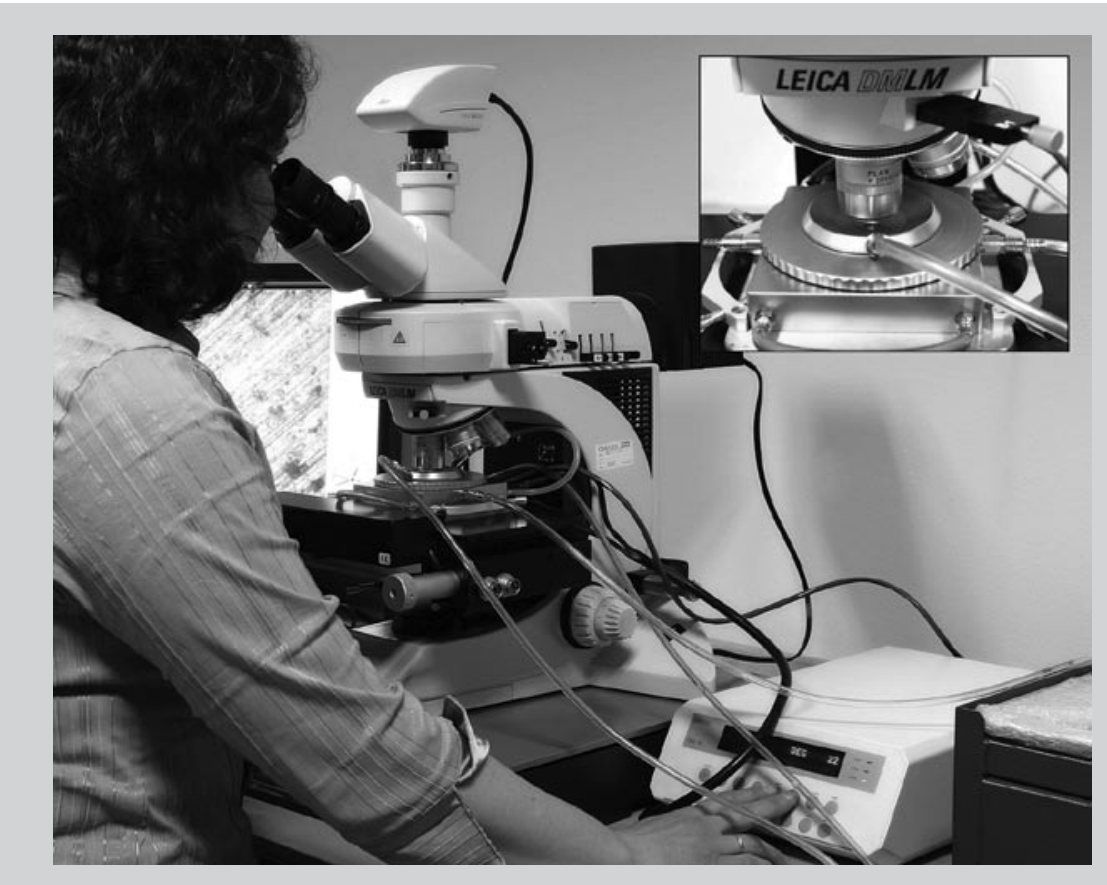

Figure 2. The hot stage microscope in use. The insert in the upper right corner shows the hot stage where the sample was heated in the chosen atmosphere. (Photo by Melinda Gaal.) 


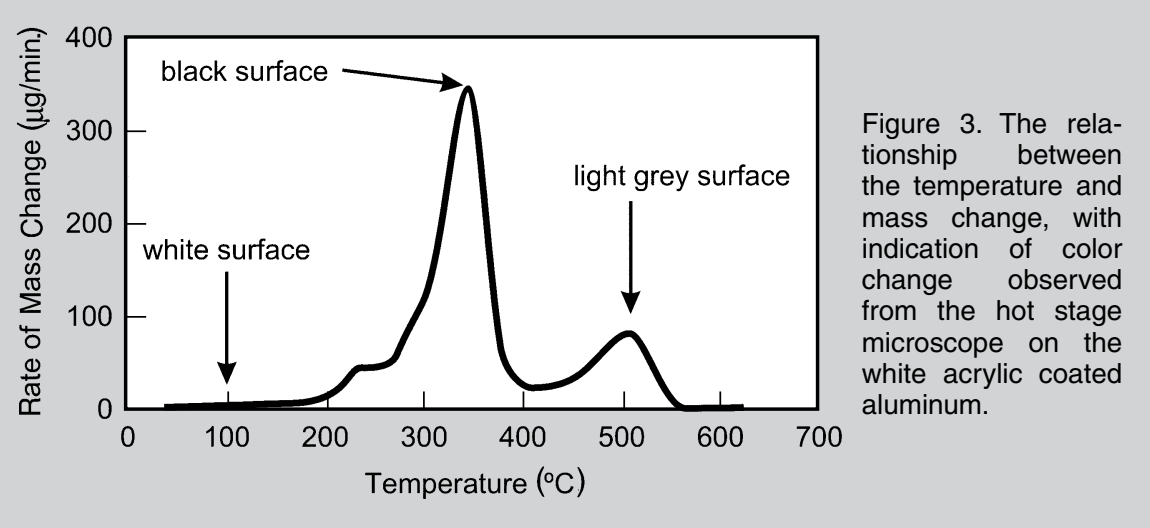

setup are described in more detail in a Ph.D. thesis. ${ }^{5}$ The composition of the remaining residues after de-coating was also determined.

In Figure 3 the observed color change registered with the hot stage microscope when heated in air at $5^{\circ} \mathrm{C} / \mathrm{min}$. is shown together with the mass-loss curve. It is seen that the mass change occurs in two main peaks corresponding to the scission regime and the combustion regime. The first peak for the scission regime takes place between $200-400^{\circ} \mathrm{C}$. The acrylic coating has a white appearance at $100^{\circ} \mathrm{C}$. During the scission regime the coating turns black as shown in the figure at the peak temperature of $340^{\circ} \mathrm{C}$. The black material is char or tar with inorganic particles. Scission is followed by combustion after $400^{\circ} \mathrm{C}$, which is completed by $550^{\circ} \mathrm{C}$. After the second peak at $565^{\circ} \mathrm{C}$ it can be seen that the surface has regained a light color.

To better visualize the de-coating process, pictures from the transparent polyester coat on aluminum heating at $5^{\circ} \mathrm{C} / \mathrm{min}$. with the hot-stage microscope

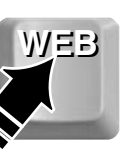
are shown in Figure 4. [Read JOM online to view video.] (a) Due to the transparency of the coating the rolling stripes in the aluminum are visible at $100^{\circ} \mathrm{C}$ before de-lacquering. (b) At the scission peak temperature, $350^{\circ} \mathrm{C}$, the surface has started to turn dark. (c) At $485^{\circ} \mathrm{C}$, corresponding to maximum mass loss during combustion, it is seen that the reaction of the carbon with oxygen starts at the pigment particles and spreads out radially. The combustion regime enlarges until the fronts merge. ${ }^{10}$ (d) At $550^{\circ} \mathrm{C}$ corresponding to minimum mass (before any oxidation) optimal de-coating and the rolling stripes are clearly visible again.

The sequence of events described here seems to take place for all acrylic and polyester coatings, independent of the substrate. This sequence has also been observed during thermal de-coating of magnesium. ${ }^{11}$ Depending on the organic components, the temperature at which the events take place can differ, but they can all be characterized in this way.

\section{EVOLVED GASES}

Representative evolved gases from acrylic coated aluminum are given in Figure 5. The mass loss curve has two distinct peaks, corresponding to the

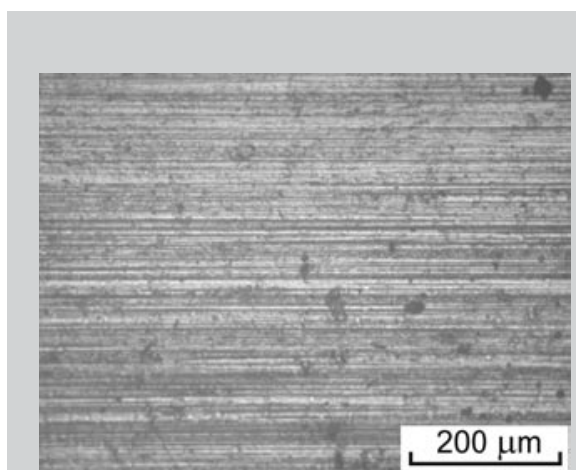

a

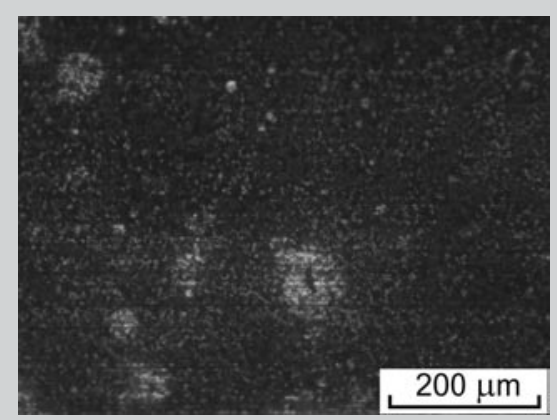

c coating completed. scission regime and the combustion regime as shown in Figure 3. For the scission regime gaSses are observed with the MS such as $\mathrm{m} / \mathrm{Z}=26,28,41$, and 87 , which all occur simultaneously. In the figure, this is shown with one typical hydrocarbon $\mathrm{C}_{2} \mathrm{H}_{2}(\mathrm{~m} / \mathrm{Z}=26)$. The gases evolved during the first peak indicate chemical degradation of the coating. This justifies the term "scission regime." Also, combustion gases, shown with $\mathrm{CO}_{2}$, are released in the scission regime. However, it is seen that the $\mathrm{CO}_{2}$ curve has a different shape. After the scission regime the signal for $\mathrm{CO}_{2}$ reaches a minimum, but there is then a new peak corresponding to the combustion regime, where only combustion gases are emitted.

The temperature range of the regimes can be coating-dependent.

\section{RESIDUES REMAINING AFTER DE-COATING}

In both oxidizing and inert atmospheres particles are left on the surface after de-lacquering, some of which are visible in Figure 4d. (When the coating is heated in argon there is also a carbon residue, similar to Figure 4b, but combustion does not occur.) Analysis

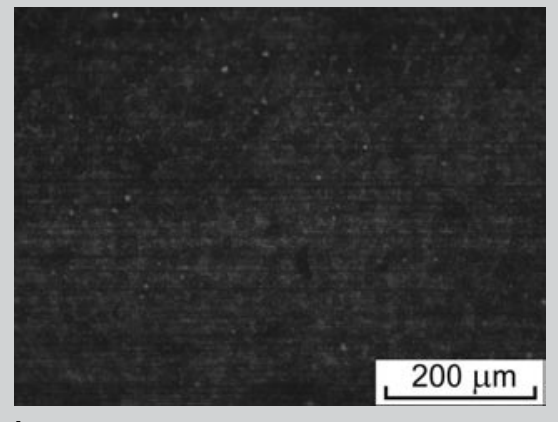

b

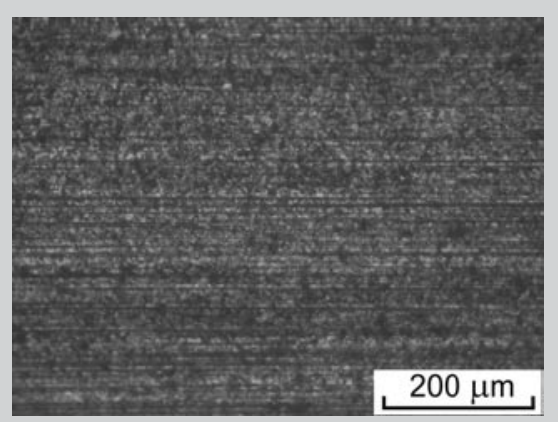

d

Figure 4. (a) At $100^{\circ} \mathrm{C}$, before de-lacquering, (b) at $350^{\circ} \mathrm{C}$, scission regime peak temperature, (c) $485^{\circ} \mathrm{C}$, combustion regime peak temperature, and (d) at $550^{\circ} \mathrm{C}$, de- 
showed that the transparent polyester coating contained $\mathrm{SiO}_{2}$ particles. The residue of four different magnesium objects is discussed elsewhere. ${ }^{12}$ These particles are common pigments, such as $\mathrm{TiO}_{2}$ and $\mathrm{Fe}_{2} \mathrm{O}_{3}$, and fillers such as $\mathrm{SiO}_{2}$.

Optimum de-coating generally comprises the removal of all organic and inorganic coating materials, which is not directly possible with thermal de-coating. Additional processing steps are required to mechanically remove inorganic particles remaining after thermal de-coating and to chemically remove other inorganic coating layers prior to re-melting of the aluminum scrap. The necessity of these steps depends on the interaction between metal, coating (residue), and salt fluxes during re-melting. The degree of interaction is determined by thermodynamics and process conditions during re-melting. ${ }^{13}$ It can be quantified using thermodynamic modeling and exergy analysis, as done for coated magnesium re-melting. ${ }^{12}$

\section{MODELING THE PROCESS}

The de-coating process can be characterized using kinetic analysis. For each mass loss peak the activation energy $E_{a}$, frequency factor $\ln A$, and reaction model $g(\alpha)$ (where $\alpha$ is the fraction of coating reacted) can be deter-

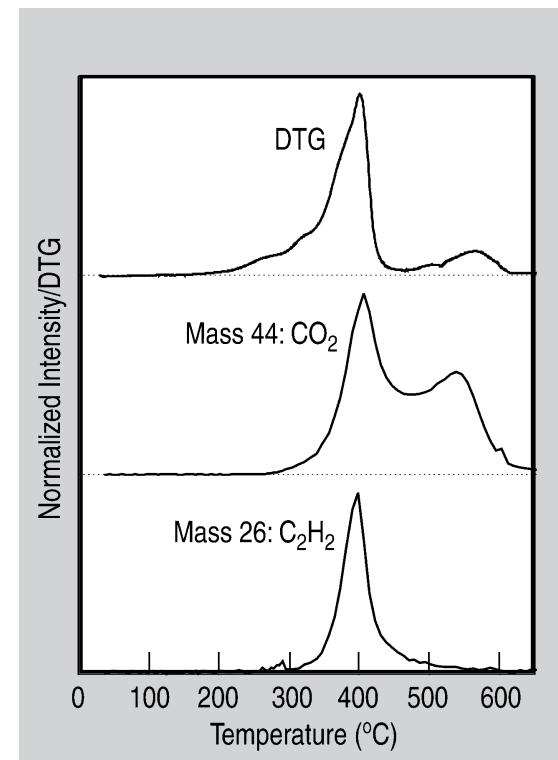

Figure 5. The mass-loss curve (DTG), with the corresponding intensity curve for $\mathrm{CO}_{2}$ and $\mathrm{C}_{2} \mathrm{H}_{2}$ evolved from a typical hydrocarbon for acrylic coated aluminum. Note that hydrocarbons are only released in the scission regime. mined. ${ }^{7} \mathrm{E}$ indicates the threshold that has to be overcome before the scission or combustion normalized mass loss takes place. The natural logarithm of A is a measure of the speed of the reaction. ${ }^{12}$

When coatings are heated it is obvious that a number of chemical reactions occur. However, one or a few reactions or mechanisms may be rate-limiting "bottlenecks." The thermo-gravimetric furnace registers the sum of these reactions by the overall mass change. This can, depending on the coating, be observed as a slightly separable peak in the scission regime. However, characterizing the scission regime with a normalized curve, even in the case of overlapping peaks, appears to be useful.

The relationship between heating rate and peak temperature is determined by the kinetics and therefore used to calculate the kinetic values. When using higher heating rates the scission and combustion regimes move to higher temperatures, as shown for the acrylic coating in Table I.

The dependence may be shown graphically by plotting the logarithm of heating rate versus the reciprocal of the absolute peak temperature. Such a plot can be used to obtain the activation energy $\mathrm{E}_{\mathrm{a}}$ from the slope calculated by the classical Kissinger method. ${ }^{5,14}$ The resulting activation energies are shown in Table II. It is seen that the activation energy of the scission regime is lower than for the combustion regime, indicating that the threshold for the scission regime is lower than what is required for combustion. These kinetics values, such as activation energy $E_{a}$ and frequency factor $\mathrm{A}$, determine the characteristics of de-coating and in this way the coating properties can be linked to process design, as shown previously. ${ }^{12}$

The kinetics are also dependent upon the atmosphere, with more oxygen initiating the scission and combustion regimes earlier, as shown in Table I. The small deviations lie within the uncertainty. Experiments with a heating rate of $30^{\circ} \mathrm{C} / \mathrm{min}$. take 21 minutes, while heating at $1^{\circ} \mathrm{C} / \mathrm{min}$. requires more than 10 hours. The same quantity of gas is evolved from the sample; however, with higher heating rates the peaks become more distinct and are easier to interpret.

\begin{tabular}{|c|c|c|c|}
\hline & $\begin{array}{l}\text { Heating } \\
\text { Rate } \\
\left({ }^{\circ} \mathrm{C} / \mathrm{min} .\right)\end{array}$ & $\begin{array}{c}\text { Scission } \\
\text { Peak } 1 \\
\left({ }^{\circ} \mathrm{C}\right)\end{array}$ & $\begin{array}{c}\text { Combustion } \\
\text { Peak } 2 \\
\left({ }^{\circ} \mathrm{C}\right)\end{array}$ \\
\hline \multirow[t]{4}{*}{$\mathrm{Ar}$} & 1 & 355 & - \\
\hline & 5 & 379 & - \\
\hline & 30 & 411 & - \\
\hline & 30 & 417 & - \\
\hline \multirow[t]{4}{*}{$\mathrm{Ar}+1 \% \mathrm{O}_{2}$} & 1 & 338 & 520 \\
\hline & 5 & 363 & 548 \\
\hline & 30 & 414 & - \\
\hline & 30 & 422 & - \\
\hline \multirow[t]{4}{*}{$\mathrm{Ar}+5 \% \mathrm{O}_{2}$} & 1 & 323 & 488 \\
\hline & 5 & 360 & 536 \\
\hline & 30 & 417 & 575 \\
\hline & 30 & 418 & 611 \\
\hline \multirow[t]{4}{*}{ Air } & 1 & 310 & 469 \\
\hline & 5 & 344 & 507 \\
\hline & 30 & 400 & 563 \\
\hline & 30 & 400 & 566 \\
\hline
\end{tabular}

\section{MONITORING, PREDICTION, AND PREVENTION}

Today de-coating efficiency is partly evaluated by visual inspection. When treating beverage cans, over-exposure is easy to see around the opening, while under-exposure is best observed by inspecting the inside of the can. The operators adjust the residence time, operating temperature, and kiln atmosphere by trial and error.

In the scission regime evolved gases from the coating are released, leaving a carbon residue and fillers/pigments. The evolved gases should ideally be captured, cleaned, and used for preheating the scrap before melting. The pigments should also be removed, otherwise they will contaminate the melt and recycling will degrade metal by "down cycling."

To prevent oxidation of metal it is especially important to accurately model and monitor the combustion regime. Ideally, the metal should exit the decoating kiln just when the combustion regime is finished and before bare metal starts oxidizing. Measuring gases such as $\mathrm{O}_{2}, \mathrm{CO}$, and $\mathrm{CO}_{2}$ is relatively simple and should be a useful tool for process control.

Also, optical observations at the end of the de-coating line should contribute 
Table Il. The Activation Energy E $(\mathrm{kJ} / \mathrm{mol})$ and the Frequency Factor A $\left(\mathrm{min}^{-1}\right)$ for Acrylic Coating in Various Atmospheres

\begin{tabular}{|c|c|c|c|c|c|}
\hline & & $\mathrm{Ar}$ & $\mathrm{Ar}+1 \% \mathrm{O}_{2}$ & $\mathrm{Ar}+5 \% \mathrm{O}_{2}$ & Air \\
\hline \multirow[t]{2}{*}{ Scission } & $\mathrm{E}_{\mathrm{a}}$ & 193.00 & 156.00 & 112.00 & 112.00 \\
\hline & $\ln A$ & 34.23 & 27.49 & 18.85 & 19.55 \\
\hline \multirow[t]{2}{*}{ Combustion } & $\mathrm{E}_{\mathrm{a}}$ & no & 261.00 & 141.00 & 152.00 \\
\hline & $\ln A$ & no & 55.05 & 37.24 & 39.65 \\
\hline
\end{tabular}

to optimizing the temperature and residence time to match the desired end of the combustion regime.

The properties and behavior of the substrate at elevated temperatures also determine the heating program that should be used during de-coating. For example, magnesium has constraints on the upper temperature limit due to oxidation of the substrate, and at even higher temperatures self-ignition may occur. The self-ignition temperature can be below the temperature necessary to completely de-compose the coating. Hence, adjustments are necessary in the temperature-time program, as well as care in the initial selection of the coating.

It should also be noted that hightemperature resistant coatings, which require de-coating temperatures above the oxidation temperature, will require an optimized process which balances the coating removal against oxidation of the metal. Alternatively, the residence time at lower temperatures could be extended. To prevent this situation an alternative, easy-to-remove coating should be selected during the design of coated aluminum products.

Modeling of the de-coating process using kinetic analysis can be carried out with a TG/DTA set-up. The obtained model parameters can be used to predict the de-coating process, the impact of changes in the temperature program and gas atmosphere, and the development of de-coating models. From the model, optimal temperature-time and atmosphere-time curves for industrial systems may be determined. The model can provide feedback to designers and manufacturers about the effect of different coatings on the recycling and de-coating process of aluminum for end-of-life products.

\section{OPERATING WINDOW}

The goal of the de-coating process is to combust all the carbonized material without oxidizing the metal. There is a fine line between too little de-coating, exactly enough, and too much decoating leading to oxidation. The window for correct treatment is believed to be small. For the polyester coating in Figure 4, the difference between lowest mass $\left(550^{\circ} \mathrm{C}\right)$ and the highest carbon consumption $\left(485^{\circ} \mathrm{C}\right)$ is only $65^{\circ} \mathrm{C}$. In addition, in Figure 4 the heating was slow $\left(5^{\circ} \mathrm{C} / \mathrm{min}\right.$.), whereas industrial units often are operated at about $20^{\circ} \mathrm{C} / \mathrm{min}$., making the residence time window smaller. Once the metal is oxidized, it is not possible to utilize it within the recycling process.

\section{CONCLUSIONS}

Light metal scrap is a valuable source of raw materials. Recycling the scrap may be accomplished by mineral processing, thermal treatment, and finally a melting step. Removal of lacquer or paint is necessary and beneficial for melt cleanliness and metal yield. The goals are to remove the organics, remove the inorganics, and prevent oxidation. With this summary article thermal removal has been investigated and discussed, which will hopefully lead to new and better de-coating practices favorable for recycling.

\section{ACKNOWLEDGEMENTS}

The authors wish to acknowledge the support of this work by The Research
Council of Norway under the strategic university program in Light Metals Technology.

\section{References}

1. M.A. Reuter et al., The Metrics of Material and Metal Ecology, Vol. 16 of Developments in Mineral Processing (Amsterdam, The Netherlands: Elsevier, 2005).

2. The International Aluminium Institute, www.world -aluminium.org/.

3. The European Aluminium Association, www.eaa net/.

4. Y. Xiao, M.A. Reuter, and U. Boin, "Aluminium Recycling and Environmental Issues of Salt Slag Treatment," Journal of Environmental Science and Health, 40 (2005), pp. 1861-1875.

5. A. Kvithyld, "Thermal De-coating of Aluminium Scrap" (Ph.D. thesis, NTNU, Trondheim, 2003).

6. V. Agarwala and K. Rajeshwar, "Paint and Coating Removal Technologies: Past, Present and Future," Corrosion (Houston, TX: NACE International, 2001). 7. S. Vyazovkin and N. Sbirrazzuoli, "Iso-conversional Kinetic Analysis of Thermally Stimulated Processes in Polymers," Macromolecular Rapid Communications, 27 (18) (2006), pp. 1515-1532.

8. J.M. Morancho et al., "Comparative Study of the Degradation Kinetics of Three Powder Thermoset Coatings," Thermochemica Acta, 419 (1-2) (2004), pp. 181-187.

9. D.F. Parra et al., "Thermal Behaviour of the Epoxy and Polyester Powder Coatings using Thermogravimetry/Differential Thermal Analysis Coupled Gas Chromatography/Mass Spectrometry (TG/DTAGC/ MS) Technique: Identification of the Degradation Products," Thermochemica Acta, 386 (2) (2002), pp. 143-151.

10. A. Kvithyld, J. Kaczorowski, and T.A. Engh, "Microscope Studies of Thermal De-coating of Aluminum Scrap," Light Metals 2004, ed. A.T. Tabereaux (Warrendale, PA:TMS, 2004), pp. 151-156.

11. C.E.M. Meskers, "Coated Magnesium Designed for Sustainability" (Ph.D. Thesis to be published, Delft University of Technology, 2008).

12. C.E.M. Meskers et al., "A Fundamental Metric for Metal Recycling Applied to Coated Magnesium," Metallurgical and Materials Transactions B, (2008) in press.

13. G. Rombach, "Verhalten mineralischer Pigmente beim Aluminium Recycling," Erzmetall, 53 (2) (2000), pp. 98-105.

14. H.E. Kissinger, "Reaction Kinetics in Differential Thermal Analysis," Journal of Analytical Chemistry, 29 (1957), pp. 1702-1706.

Anne Kvithyld and Sean Gaal are with SINTEF Materials and Chemistry, N - 7465 Trondheim, Norway; C.E.M. Meskers is with Umicore Precious Metals Refining, A. Greinerstraat 14, BE 2660 Hoboken, Belgium, and Delft University of Technology, Department of Materials Science and Engineering, Mekelweg 2, 2628CD Delft, The Netherlands; Markus Reuter is with Ausmelt Australia, 12 Kitchen Rd, Dandenong, Melbourne, Victoria 3175, Australia; and Thorvald Abel Engh is with the Norwegian University of Science and Technology, N-7491 Trondheim, Norway. Dr. Kvithyld can be reached at Anne.Kvithyld@sintef.no. 